\title{
An Interactive Study on the Exchange Rate of RMB, Real Interest Rate and Real Estate Price Fluctuation
}

\author{
Jianping Yang ${ }^{1, a}$, Li He ${ }^{2, b}$ \\ ${ }^{1,2}$ School of Management, Xi'an University of Architecture and Technology, Xi'an710055, China. \\ a407287342@qq.com, b405190462@qq.com
}

Keywords: RMB exchange rate, real interest rate, real estate price, TVP-SV-VAR model.

\begin{abstract}
In the process of our country gradually expanding the degree of opening to the outside world, promoting the interest rate market and improving the real estate market, the study on the interactive relationship among RMB exchange rate, the real interest rate and the price of real house price is important. In this paper, the TVP-SV-VAR model is used to analyze the dynamic relationship between the three of them with the data from February 2015 to February 2008. The research results show that: the interaction between the RMB exchange rate, the real interest rate and the house price is time-varying, which has different influence on the different environment and backgrounds. Based on the interactive relationship between the three and its impact on China's financial stability, the paper puts forward that enhance the independence of monetary policy, weaken the money supply effect with the RMB appreciation, diversify financing channels, weaken the housing prices on bank credit amplification, and the establish pricing mechanism of market interest rate and other policy recommendations.
\end{abstract}

\section{Introduction}

In the context of building a new open economy, deepening exchange rate reform and interest rate market, this paper mainly studies the interactive relationship between RMB exchange rate, real interest rate and housing price fluctuation. Whether will one of the variables change the other variables? How to influence? Is the impact a single one or variable? At present, in this research field, most of the literature only study the relationship between the two variables, and basically use the traditional VAR model for empirical research. In this paper, it researches the dynamic relationship between the three models by using the vector auto regression model (TVP-SV-VAR model) with random fluctuations. This research method and research conclusions are different from the previous, it not only has practical significance, but also is the innovation of this paper.

\section{Survey}

At present, there are many scholars who study the relationship between two of the exchange rate, the real interest rate and the fluctuation of housing price, but there is not much literature on the dynamic relationship between the three variables.

In terms of the domestic research situation, the theoretical results are relatively few. By reviewing the domestic and abroad literature, many scholars have done a great contribution to the study of the RMB exchange rate, real interest rate and housing price fluctuation, however, most of them only have a positive analysis of the relationship between two of them. On this basis, with real interest rate as the intermediary, the paper analyzes the dynamic relationship between RMB exchange rate, real interest rate and housing price fluctuation by the combination of theoretical analysis and empirical research.

\section{Empirical model}

TVP-SV-VAR model.Consider the following VAR model:

$$
y_{t}=X_{t} \beta_{t}+A_{t}^{-1} \sum_{t} \varepsilon_{t}, t=s+1, \cdots, n
$$


Coefficient $\beta_{t}$ of formula $、$ Parameter ${ }_{t}$ and $\sum_{t}$ are all changing over time. According to Primicer (2005), $\alpha_{\mathrm{t}}$ represents accumulation variable in the lower triangle elements of matrix $\alpha_{\mathrm{t}}$, Logarithmic random volatility matrix $\mathrm{h}_{t}=\left(\mathrm{h}_{1 \mathrm{t}}, \cdots, \mathrm{h}_{\mathrm{kt}}\right)^{\prime}$, and for all $\mathrm{j}=1, \cdots, k, \mathrm{t}=\mathrm{s}+1, \cdots, \mathrm{n}$, 设 $\mathrm{h}_{\mathrm{jt}}=\ln \sigma_{\mathrm{jt}}^{2}$. All parameters in the model TVP-SV-VAR follow random walk process, that is:

$$
\begin{aligned}
& \beta_{\mathrm{t}+1}=\beta_{t}+\mu_{\beta t} \\
& \alpha_{\mathrm{t}+1}=\alpha_{t}+\mu_{\alpha t} \\
& h_{\mathrm{t}+1}=h_{\mathrm{t}}+\mu_{\mathrm{ht}}
\end{aligned} \quad, \quad\left(\begin{array}{c}
\varepsilon_{\mathrm{t}} \\
\mu_{\beta \mathrm{t}} \\
\mu_{\alpha \mathrm{t}} \\
\mu_{\mathrm{ht}}
\end{array}\right) \square\left(0,\left[\begin{array}{cccc}
1 & 0 & 0 & 0 \\
0 & \sum_{\beta} & 0 & 0 \\
0 & 0 & \sum_{\alpha} & 0 \\
0 & 0 & 0 & \sum_{\mathrm{h}}
\end{array}\right]\right)
$$

Among them, $\beta_{\mathrm{s}+1} \square N\left(\mu_{\beta 0}, \sum_{\beta 0}\right), \alpha_{\mathrm{s}+1} \square N\left(\mu_{\alpha 0}, \sum_{\alpha 0}\right), \mathrm{h}_{\mathrm{s}+1} \square N\left(\mu_{\mathrm{h} 0}, \sum_{\mathrm{h} 0}\right)$. If the impact of variable parameters is not relevant, and $\sum_{\beta} 、 \sum_{\alpha}$ and $\sum_{\mathrm{h}}$ are all diagonal matrix. In formula (5), assume that all parameters follow a random walk process, Primicer (2005) pointed out that the assumption may allow the parameters to be temporarily or permanently changed, which can capture the change or mutation of the potential economic structure. For the estimation of the model, Nakajima (2011) thought that A.A.Markov (MCMC) method was more accurate and effective.

The instruction of data selection.In this paper, it takes the exchange rate of RMB against the U. S. dollar as a representative of the exchange rate, expressed as E, and the data is from the people's Bank of China website. Our country's interest rate has its own unique structure, the choice of interest rate index needs to combine the theoretical analysis in the third chapter and the actual situation of our country. On the basis of the existing literature, Zhe Wang (2008) raised a practical interest rate calculation method, which is based on the data obtained, that is, the real interest rate (RI) is market 7 days' buying back interest rate from the inter-bank minus the CPI. This paper uses the method of calculation proposed by Zhe Wang (2008) to calculate the real interest rate, represented as $\mathrm{R}$, the market 7 days' repo rate of the inter-bank bond is from China's currency net, and China's consumer price index CPI monthly data is from the Wind Information. Real estate prices fluctuate frequently, the annual and quarterly data is not sufficient to describe its volatility characteristics, therefore, this paper uses the housing sales price index from monthly data, represented as P. In view of the fact that the housing sales price index is available, the time span of data is using the national housing sales price index from December 2008 to March 2010, and since 2011, the National Bureau of statistics is no longer issuing the old version of the housing sales price index, so from February in 2011 to February in 2015, this paper uses the new version of the housing index, namely taking Beijing as a representative, it takes the new commercial housing prices index to represent the housing sales price index, which sources the "China Economic Report" and the website of the National Bureau of statistics, the nominal target are transformed as the actual index. The actual effective exchange rate data is from the international clearing site (http://www.bis.org/) and the National Bureau of statistics website. Other data sources from the "China Statistical Yearbook" of calendar year. Measurement analysis software is OxMetrics6. In order to make the data have comparability, the three variables are treated with the logarithm processing, and the data are expressed in the lower case (e, r, p).

\section{Empirical Analysis}

According to the theoretical model analysis, this paper sets the variable order of the empirical model as the RMB exchange rate $(\mathrm{E})$, the real interest rate $(\mathrm{R})$ and the real estate price $(\mathrm{P})$. OxMetrics6 is used to process the model TVP-SV-VAR, the lag period of the model is 2, and the sampling times of MCMC is 10000 . 


\section{Stationary test}

Table1 Sequence unit root test

\begin{tabular}{|c|l|l|l|l|l|}
\hline variable & $\begin{array}{l}\text { Test type } \\
\text { C、T、L })\end{array}$ & $\begin{array}{l}\text { ADF } \\
\text { statistics }\end{array}$ & $\begin{array}{l}1 \% \text { critical } \\
\text { value }\end{array}$ & $\begin{array}{l}5 \% \text { critical } \\
\text { value }\end{array}$ & conclusion \\
\hline $\mathrm{E}$ & C、O、 2 & -0.914517 & -3.513344 & -2.897678 & unstable \\
\hline$\Delta \mathrm{E}$ & C、0、1 & -4.543071 & -3.514426 & -2.898145 & stable \\
\hline $\mathrm{R}$ & $\mathrm{C}, 0 、 1$ & -2.743071 & -3.513344 & -2.897678 & unstable \\
\hline$\Delta \mathrm{R}$ & C、0、0 & -5.081597 & -3.514426 & -2.898145 & stable \\
\hline $\mathrm{P}$ & C、0、0 & -2.530692 & -3.512290 & -2.897223 & unstable \\
\hline$\Delta \mathrm{P}$ & $\mathrm{C} 、 0 、 0$ & -3.155071 & -3.513344 & -2.897678 & stable \\
\hline
\end{tabular}

Notes: (1)C, T and L represent constant term, temporal trends, and lag in the ADF test types, value of 0 indicates that there is no such; (2) $\Delta$ represents first order differential.

Analysis on parameter estimation result
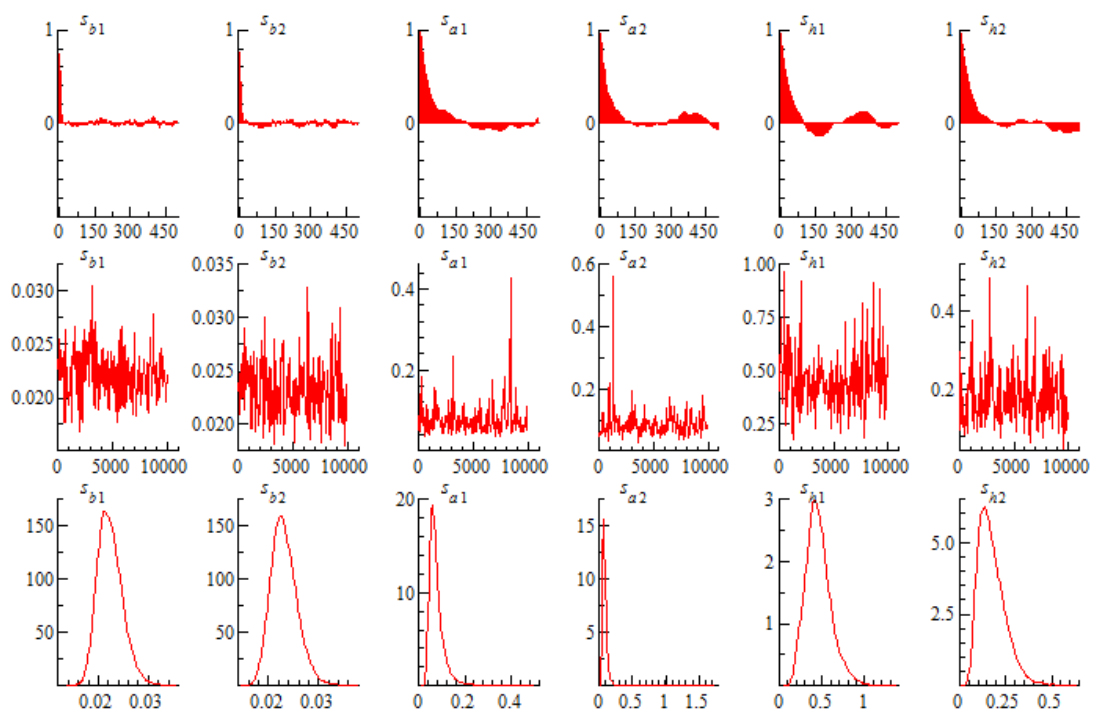

Fig. 1 Parameter estimation results of modal TVP-SV-VAR

\section{The analysis on time varying impulse response}

Fig. 2 and fig. 3 show that the two types of impulse response function in the TVP-SV-VAR model, in which figure 2 states the impulse response in different time points. The comparison time is in July 2008, July 2009 and November 2012, which are randomly selected; Fig. 3 shows the practical sequence of impulse response of a unit of different lead times. 

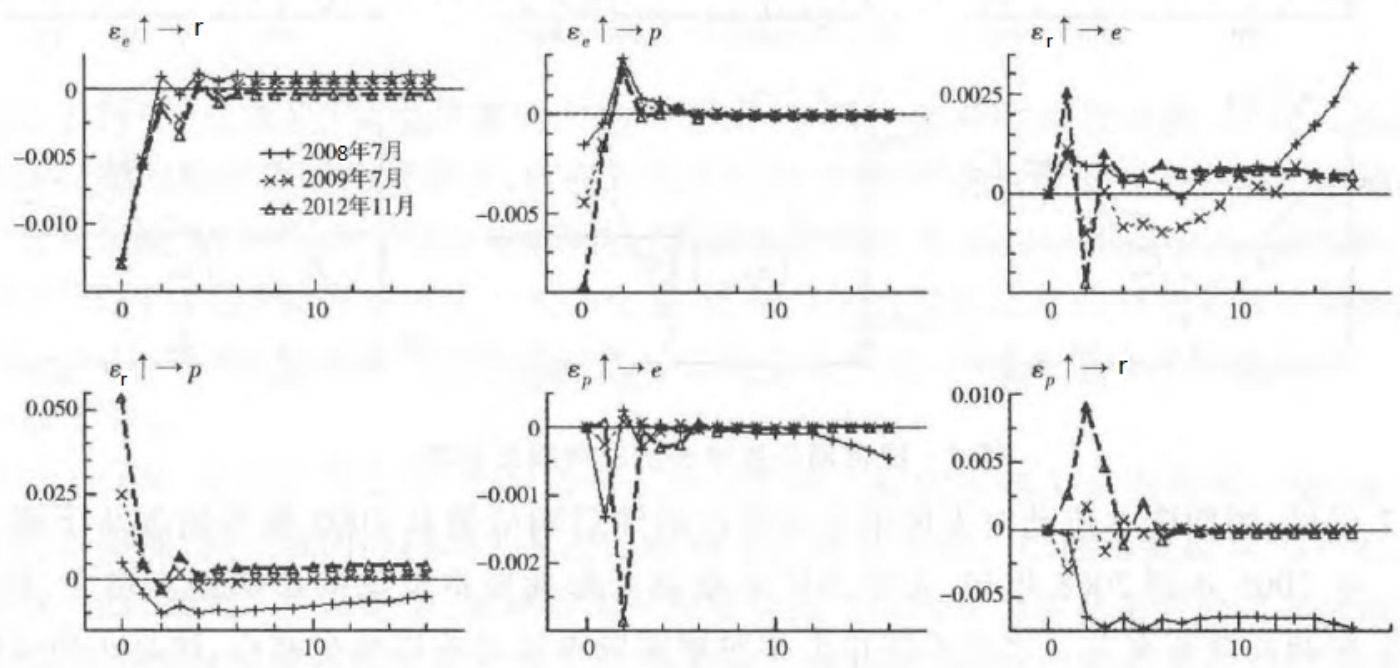

Fig. 2 Impulse response function in different time points

The varying feature analysis of impulse response in different time points .From Fig. 2, although the three impacts are applied at three different time points, the changing trend of the function is similar. Current real interest rates has an impact on the response of RMB exchange rate, and it has achieved the maximum, then gradually become small, to the sixth phase, the impulse response is almost 0 . Similarly, real estate prices has an impact on the response of RMB exchange rate, and it achieves maximum, then gradually reduces, in the third phase, the impulse response is changed to integrity and it is changed closely to 0 in the sixth phase.

For the impulse response in three time points, the response impact the housing price has on the real interest rate is similar in numerical changes, but it is different in the direction of lagging. The impact of house prices on the real interest rate is positive in the current period, followed by a trend of decreasing and performing stable and slow rise after the forth stage.

Analysis on time-varying characteristics of impulse response in different advance time. Fig. 3 shows the time series of impulse response of a unit of a standard in different advance time, and the advance time is period 1, 3 and 5 representatively. From Figure 3, the impulse response function in three different time period is similar, it is different in direction in different advance time.
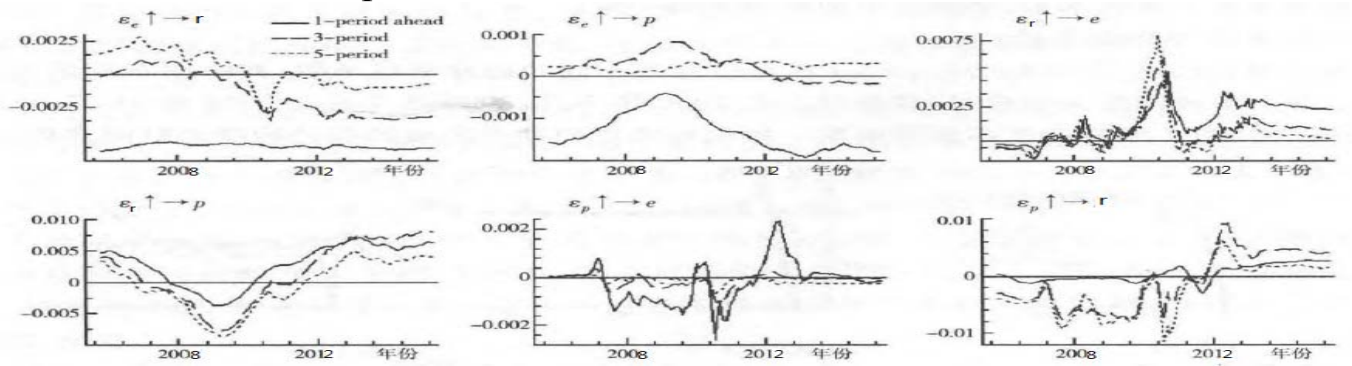

Fig. 3 Impulse response function of exogenous shock in advance

From Fig.3, it can be seen that the lagged response values of the impact the real interest rate on the RMB exchange rate begin to gradually decline and perform negative. From 2008 to the beginning of 2012, the impact of the RMB exchange rate fluctuations on the real interest rate gradually increased and then decreased, which is due to the U.S. subprime mortgage crisis in the United States, the RMB peg to the U.S. dollar, the role the exchange rate played in the real interest rate are declining.

\section{Conclusion}

Through the above analysis, we find out that the relationship among the exchange rate, effective interest rate and housing price is not a simple and single one; On the contrary, the relationship vary under different conditions and environment, and it changes constantly over time. Previous studies suggested that there is only a single correlation among the three factors, however, the interactive 
relationship among them is time-varying and complex. Through analyzing the linkage model of exchange rate, effective interest rate and housing price, we can figure out that the exchange rate appreciation could lead to a rise in the effective interest rate, and vise versa; a decline in the effective interest rate could cause a rise in housing prices; the effective interest rate, which acts as a bridge, could establish a relationship between exchange rate and housing price, however, the exchange rate appreciation could not necessarily evoke a rise in housing price, meanwhile, the housing price may affect the exchange rate either in a positive way or negative way. Through observing the time varying parameter of TVP-SV-VAR model, we can point out that the impact of the $\mathrm{RMB}$ exchange rate on the effective interest rate is relatively stable, and the influence the effective interest rate has on the housing price of China is increasing gradually. The fact confirms the hypothesis that the effective interest rate is the link between the RMB exchange rate and the housing price, and there is a growing influence of the exchange rate on the housing price.

\section{References}

[1] Ba Shusong, Yanmin. "The Dynamic Relationship between the Share Price and the Exchange Rate ------ An Analysis based on Chinese Market”. Nankai Economic Research. 2009(3)

[2] Wang Aijian, Linnan. "A Study On the Dynamic Relationship between the RMB Nominal Rate and the Interest Rate". Economic Research. 2007, (10):56-67

[3] Guo Shuhua. "Empirical Research On the Relationship between Chinese and US Interest Rate: 2005-2008[J]”. International Finance Research, 2009,(4):17-24.

[4] He Huigang. "Empirical Analysis and Countermeasure Study of RMB Interest Rate and Exchange Rate Fluctuations". International Finance Research, 2008, (8):51-57.

[5] Zhao Tianrong, Li Cheng. "The Dynamic Relationship between the RMB Exchange Rate and the Interest Rate ---- Empirical Research based on the VAR-GARCH Model". Statistical Research, 2010,(2):72-76.

[6] Gaobo, Mao Zhonggen. "The Exchange Rate Shock and the Property-value Bubble: International Experience and Chinese Policy-oriented Research". Economic Theory and Management, 2006(2)

[7] Zhou Jingkui. " The Impact of the Adjustment of Interest Rate and Exchange Rate on the Housing Price ----- A Research based on Theory and Experience". Finance Theory and Practice, 2006(12)

[8] Xu Weixun. “The Influence of RMB Exchange Rate Has on the Housing Price”. Research Paper of Guangdong University of Foreign Studies, 2008 